\title{
Design and Experimental Characterisation of an Additively Manufactured Heat Exchanger for the Electric Propulsion Unit of a High-Altitude Solar Aircraft
}

\author{
Rafal Wrobel, Ben Scholes, Ahmad Mustaffer, Sana Ullah, David Reay, Barrie Mecrow \\ School of Engineering, Newcastle University, Newcastle upon Tyne, UK \\ rafal.wrobel@newcastle.ac.uk \\ Ahmed Hussein \\ HiETA Technologies Ltd., Bristol, UK \\ ahmedhussein@hieta.biz
}

\begin{abstract}
This paper presents design considerations of an air-cooled heat exchanger (HE) for a propulsion motor. The motor has been designed as a part of electric drive system for a high-altitude solar aircraft. The existing heat evacuation methods for such applications include predominantly forced air ventilation of the machine active parts through an open frame/motor housing. When considering numerous constraints associated with the airframe design, the effectiveness of such a cooling approach might be insufficient or have a detrimental impact on the system endurance. This is due to the resultant air flow via the motor body, which is rather difficult to reliably model or design for. In this work, the authors investigate a dedicated heat exchanger to assure a more measured design with superior cooling capability. To enable sufficient heat removal from the motor body, a metal additive manufacture (AM) was used in fabrication of the HE prototypes. Both design methodology and experimental results from tests on the $\mathrm{HE} /$ motor hardware demonstrators are discussed in detail. The research outcomes have shown that the use of the developed thermal management system offers a high level of motor/HE integration, lightweight design and a high removal rate of the generated heat.
\end{abstract}

Keywords-heat exchanger, thermal management, electric motor, electric propulsion, solar aircraft

\section{INTRODUCTION}

This work reports on development of a heat exchanger (HE), which is a part of an electric propulsion system for a high-altitude solar aircraft. Such unmanned aerial vehicles (UAV) are intended to be pseudo satellites, operating continuously in the earth's stratosphere for months or even years. Here, the research focus has been placed on thermal management of the electric motor designed for such a purpose [1]. Operating specifics of the high-altitude solar plane require two working modes of the motor to be satisfied. The first one is at the assisted launch of the plane, where relatively hightorque is demanded, whereas the second one is at the highaltitude cruise, where high-efficiency operation is needed [2], [3]. It is important to note that the solar aircraft is intended for long-duration endurance flights. Therefore, the motor design exercise has several interesting challenges [1]-[3].

When considering a lightweight and compact motor, an appropriate design must ensure that both the take-off and cruise design criteria are met and well balanced [1]-[3]. A good understanding of the intended operation of the plane is a prerequisite of an optimal motor design. This must harness the air stream entering the motor body during the flight to reduce the overall motor size and extend flight endurance. In this context, thermal management of the motor is particularly important at the take-off, where the generated power loss is eight times larger than for the cruise operating mode [1].

In this investigation, the high-altitude operation is limited to $20 \mathrm{~km}$ with the air temperature and pressure ranging from $+45^{\circ} \mathrm{C}$ to $-85^{\circ} \mathrm{C}$ and from $101.3 \mathrm{kPa}$ to $5.5 \mathrm{kPa}$ at sea level and $20 \mathrm{~km}$, respectively. When considering the high-efficiency motor operating at low ambient temperature, the cruise operation is less demanding when it comes to thermal management, although, it is important to note that the air density is approximately 14 times lower at $20 \mathrm{~km}$ than at sea level. Consequently, careful considerations need to be taken when accounting for convective heat transfer from the motor body both for the high-torque and high-efficiency modes.

Existing examples of motors for high-altitude solar aircraft application are predominantly variants of brushless ac outer rotor, surface mounted permanent magnet (PM) topologies [1]-[3]. Such motors are usually designed with an open-frame to encourage air flow through the machine body and statorwinding in particular, and to minimise mass of the complete machine assembly. However, dissipative heat transfer from the open-frame motor design is limited by the overall motor's size and air speed among many other factors. In this paper, the authors propose the use of an air-cooled HE to provide the main dissipative heat transfer from the open-frame motor design.

The proposed HE is specifically designed to assure sufficient heat removal from the stator-winding assembly during the aircraft ascent. In this paper, the authors outline the key considerations for the HE design, supplemented with a methodology for deriving the final HE design. Information from hardware development of the HE and experimental setup build is also discussed. Further to this, calculated and measured data from characterising the HE/motor performance is included. The results show that the proposed HE design meets the design targets. The practical system implementation however, is subject to appropriate aerodynamic design of the motor enclosure, guiding the air stream into the motor/HE body, which is beyond the scope of this paper. 
a)

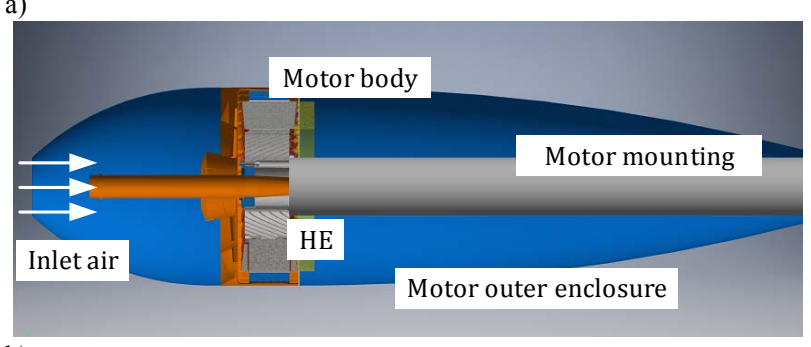

b)

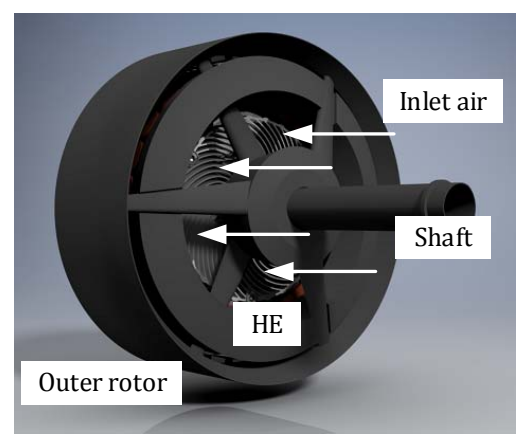

c)

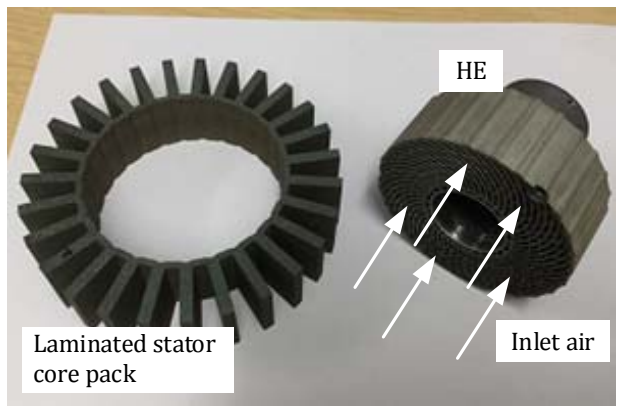

Fig 1. Motor assembly, a) schematic representation of the complete motor together with aerodynamic enclosure, b) outline of the motor assembly together with $\mathrm{HE}, \mathrm{c})$ prototype laminated stator core pack and $\mathrm{HE}$

\section{PROPULSION MOTOR CONSTRUCTION}

Following on from previous evolutions of electric motors for high-altitude solar planes, a motor topology with outer rotor and surface mounted PMs has been employed here [1][3]. Specifically, the outer rotor motor is well suited for directdrive applications, giving improved specific-output compared to an inner rotor counterpart, assuming identical mechanical space-envelope for both topologies. A 27 slot and 36 pole motor design has been chosen following the design trade study [1]. The motor's magnetic circuit includes ultra-low power loss electrical steel $(0.1 \mathrm{~mm} \mathrm{FeSi}, \mathrm{Si}-6 \%)$ for both stator and rotor assemblies, and rare earth laminated PMs ( $\mathrm{NdFeB})$. The stator's open-slot construction has a double-layer concentrated winding, which is formed using aluminium conductors. This, together with a composite carbon-fibre housing, provides a lightweight motor assembly. To compensate for poorer electrical properties of the aluminium conductors, compressed coils with high conductor fill factor $(75 \%)$ are used here. The heat exchanger and stator-winding interface via the stator inner bore.

Fig. 1a) presents a schematic representation of the motor together with the outer enclosure. The enclosure's aerodynamic design is to provide sufficient air-flow into the heat exchanger body. Here, an air-flow speed in the range $1.0 \mathrm{~m} / \mathrm{s}$ to $7.0 \mathrm{~m} / \mathrm{s}$ is considered, with the lower end practically achievable. The complete motor assembly is shown in Fig. 1b). The open-frame allows for the air-stream to enter the heat exchanger. Fig. 1c) shows the fabricated stator core pack and $\mathrm{HE}$ assemblies. It is important to note that the HE design needs to provide sufficient heat extraction from the stator-winding body as well as mechanical support for the complete motor assembly. As the HE is required for take-off only, it is also vital that it's weight is minimised. An approximate power output per motor is $600 \mathrm{~W}$ at $1000 \mathrm{rpm}$. The power delivery during take-off is approximately constant with the initial (sea level) torque demand, which is 3 times larger than for highefficiency (95\%), high-altitude $(20 \mathrm{~km})$ cruise operation.

The majority of the power loss generated during take-off is associated with the stator-winding assembly (high-torque, low-speed/low-frequency operation). This is where the HE is particularly important to evacuate the generated heat. The aircraft full ascend is relatively slow, taking several hours. Consequently the thermal duty is such that the motor operates at thermal equilibrium with a gradual change of the ambient/inlet air temperature and pressure. The cruise operation (low-torque, high-speed/high-frequency operation) results in various ac effects, leading to additional power losses, which need to be carefully considered to realise the high-efficiency operation [4], [5]. This is notoriously difficult to achieve for small and low-power machines. Here, the outer mechanical envelope of active parts is approximately $\emptyset 130 \mathrm{~mm}$.

\section{HEAT EXCHNGER DESIGN}

\section{A. Topology Selection and Construction}

There are a number of unique design requirements associated with thermal management of the solar aircraft, particularly when combined operation includes take-off from hot regions of the world and then high-altitude (lowtemperature, low-pressure) cruise. As highlighted in the previous section, the take-off transient is the most demanding for the motor and its thermal management system. It is vital that thermal resistance between heat sources and heat sink, e.g. stator-winding assembly and HE body, is 'low' providing a 'good' thermal path for removing the generated heat. In principle, designing a cooling system providing sufficient heat rejection for the analysed motor is relatively straightforward. However, when considering the application and constraints regarding weight and volume of the system, the design exercise becomes rather challenging. In this context, the use of additive manufacturing (AM) enables new design avenues, which were previously not possible [6]. A number of HE concepts were considered prior to the design employed in the solar plane. These include in-fin arrangements (which would be insensitive to the approaching flow direction, wire HEs (offering a high surface/volume ratio) and conventional fins [7]. Of all the solutions examined, it was decided to select a more conventional air-cooled HE that potentially offered the lightest, most compact solution, which is also simple to integrate within the machine body. The selected HE is unusual in that it is fabricated using additive manufacturing and gives an extremely high active surface area to volume ratio $2696 \mathrm{~m}^{2} / \mathrm{m}^{3}$, which would not be possible to achieve using more conventional manufacturing methods. The geometry of the first iteration of HE is shown in Fig. 1c). The use of appropriate materials in construction of the HEs is a prerequisite of compact, high-performance design. Titanium alloys were initially considered in the design process, but due to their relatively low thermal conductivity they were replaced by aluminium alloys. The HE was manufactured using a Renishaw AM250 machine equipped with a 200W single 
laser. The powder material used was AlSi10Mg with approximate particle sizes ranging from 10 micron to 50 micron. The layer thickness used during manufacturing was 25 micron.

\section{B. Design Methodology}

The initial design of the HE exchanger has been performed using a simplified one-dimensional (1D) analytical approach, supplemented later with a more detailed analysis using threedimensional (3D) computational fluid dynamic (CFD) analysis. The underpinning fundamentals of analytical design and analysis of compact HEs have been discussed by several authors [8], [9] and focus on both the pressure-drop and heat transfer effects. These two factors are discussed in the subsequent paragraphs.

\section{1) Pressure-Drop Modelling}

The overall pressure-drop across the HE body can be expressed as follows,

$$
\begin{aligned}
\Delta P_{\text {total }}=\frac{G^{2}}{2 g \rho_{i}}[ & \left(1-\sigma^{2}+K_{c}\right)+2\left(\frac{\rho_{i}}{\rho_{o}}-1\right) \\
& +f\left(4 \frac{L}{D_{h}}\right)\left(\frac{\rho_{i}}{\rho_{m}}\right) \\
& \left.-\left(1-\sigma^{2}-K_{e}\right)\left(\frac{\rho_{i}}{\rho_{o}}\right)\right]
\end{aligned}
$$

where: $G$ is the mass flux, $\sigma$ is the ratio of minimum free flow to frontal areas of the HE, $f$ is the fanning friction factor of the HE core geometry, $D_{h}$ is the hydraulic diameter, $\rho_{i}$, $\rho_{o}$ and $\rho_{m}$ are the inlet, outlet and mean fluid densities, $g$ is the acceleration due to gravity, $K_{c}$ and $K_{e}$ are the inlet and outlet loss coefficients, and $L$ is the HE core length.

The coefficients $K_{c}$ and $K_{e}$ are a function of $\sigma$, Reynolds number, $R e$, and geometric shape of HE body and can be determined from the curves provided in [8]. The fanning friction factor is derived using experimental data from pressure-drop tests on HE hardware, see Appendix for more details.

\section{2) Heat Transfer Modelling}

The formulae used in determining the HE heat transfer rate can be written in the following form,

$$
Q=\left(\dot{m} c_{p}\right) \Delta T
$$

where: $Q$ is the heat transfer rate, $\dot{m}$ is the mass flow rate, $c_{p}$ is the specific heat capacity and $\Delta T$ is the temperature difference between inlet and outlet fluid (air).

Based on the averaged heat transfer rate, $Q_{\text {avg }}$ and logarithmic mean temperature difference for cross air-flow, $\Delta T_{L M T D_{\text {cross }}}$, a product of the overall $\mathrm{HE}$ heat transfer coefficient, $U$, and heat transfer area, $A_{\text {exp }}$, can be found,

$$
\begin{aligned}
& U A_{\text {exp }}=\frac{Q_{\text {avg }}}{\Delta T_{L M T D_{\text {cross }}}} \\
& \Delta T_{L M T D_{\text {cross }}}=F \Delta T_{L M T D_{\text {counter }}} \\
& \Delta T_{L M T D_{\text {counter }}}=\frac{\Delta T_{2}-\Delta T_{1}}{\ln \left(\frac{\Delta T_{2}}{\Delta T_{1}}\right)}
\end{aligned}
$$

where: $\Delta T_{1}$ and $\Delta T_{2}$ are the temperature differences between 'hot' and 'cold' fluids at the HE inlet and outlet respectively, and $F$ is the correction factor for the HE cross air-flow. from:

The overall thermal resistances of the HE can be derived

$$
\frac{1}{U A_{\text {exp }}}=\frac{1}{\left(\eta_{o} A h\right)_{h o t}}+R_{w}+\frac{1}{\left(\eta_{o} A h\right)_{\text {cold }}}
$$

where: $\eta_{o}$ is the overall surface efficiency, $R_{w}$ is the wall thermal resisatnce and $h$ is the het transfer coefficient. More detials on derivation of the parameters witnin (5) are provided in the Appendix.

\section{3) Empirical and CFD Analysis}

Clearly, use of the analytical approach is limited as it does not account for all the complex fluid dynamic effects occurring in the HE body. Consequently, a degree of experience is required to derive an initial HE geometry. Here, an expert knowledge was used, where empirically derived data from previous HE developments together with CFD analyses were employed to inform the $1^{\text {st }}$ iteration of the HE exchanger prototype [6]. Fig. 2 illustrates intricate air flow patterns derived from the early CFD analyses with unblocked and blocked air passages through the motor body. The results give better understanding of all performance gains of implementing the HE, as compared with a more conventional motor design with a simple ventilation. The initial work was focused on assuring a sufficient heat removal from the statorwinding assembly via the integrated $\mathrm{HE}$ at a minimal added weight to the overall motor assembly. This led to a highly integrated mechanically, but conservative thermally, HE design with a relatively dense core ( $1^{\text {st }}$ iteration of $\left.\mathrm{HE}\right)$.

a)

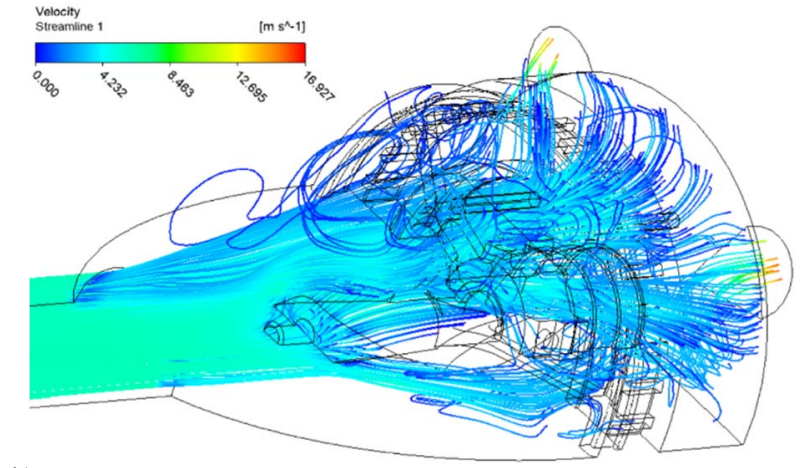

b)

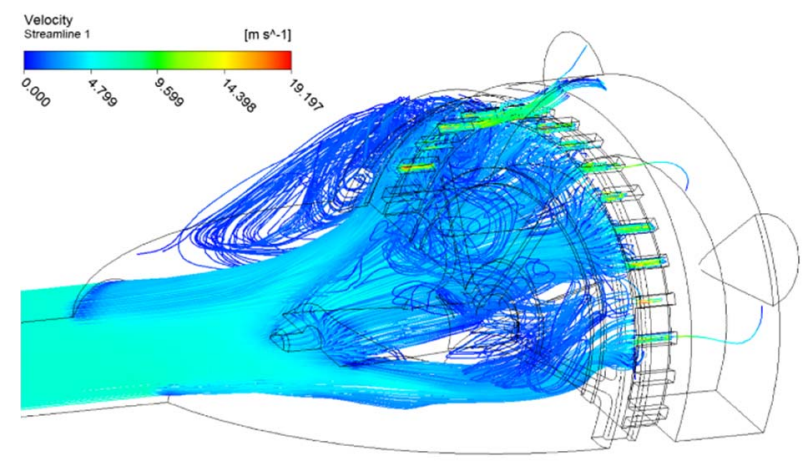

Fig. 2. Initial results from CFD analyses of the complete motor assembly with blocked a) and unblocked b) passage through the motor body 


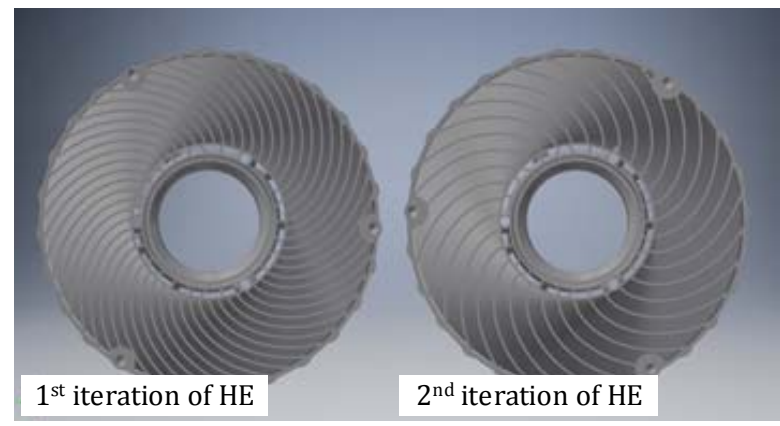

Fig. 3. Schematic representation of the $1^{\text {st }}$ and $2^{\text {nd }}$ iteration of the HEs' core

Fine tuning of the HE was performed ( $2^{\text {nd }}$ iteration of HE) to assure a 'low' pressure-drop across HE core. This is to encourage a sufficient airflow speed into HE, as a result of the aircraft motion. Fig. 3 schematically presents the core for both $1^{\text {st }}$ and $2^{\text {nd }}$ iterations of the HE. It is important to note that reducing the pressure-drop has an adverse impact on the $\mathrm{HE}$ heat removal capability. Consequently, an iterative design approach was employed here, to provide both 'low' pressuredrop and 'high' heat removal.

\section{EXPERIMENTAL WORK}

\section{A. Wind Tunnel Construction}

A detailed analysis of the exact model representation of the HE exchanger and associated motor subassembly would be computationally prohibitive. Thus, an experiment informed design approach has been employed here, using a low-scale wind tunnel. Fig. 2 shows the experimental setup used to characterise HE performance, to supplement the theoretical body of work discussed earlier. The key elements of the wind tunnel include the speed controlled fan, airflow conditioner, airflow speed and pressure-drop measuring instruments, heating element and thermal enclosure. The airflow conditioner was constructed using a set of honey comb extrusions and mesh to assure a well-defined 'straight' airflow into the HE body [12], [13]. The flow velocity is measured

a)

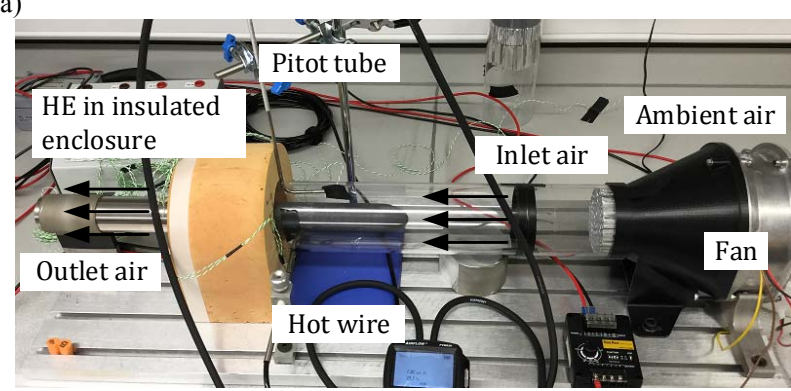

b)

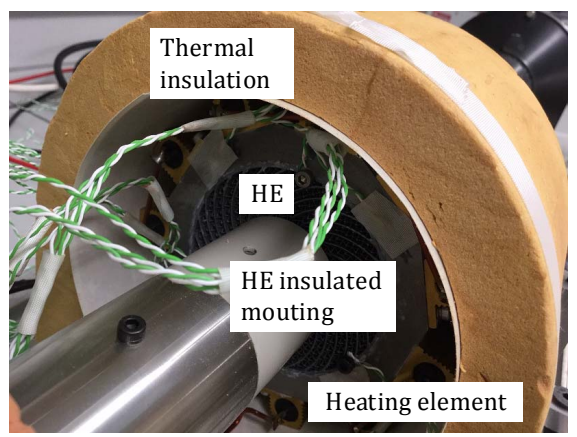

Fig. 4. Low-scale wind tunnel experimental setup for characterising HE variants, a) complete test rig, b) $\mathrm{HE}$ with heating element in place

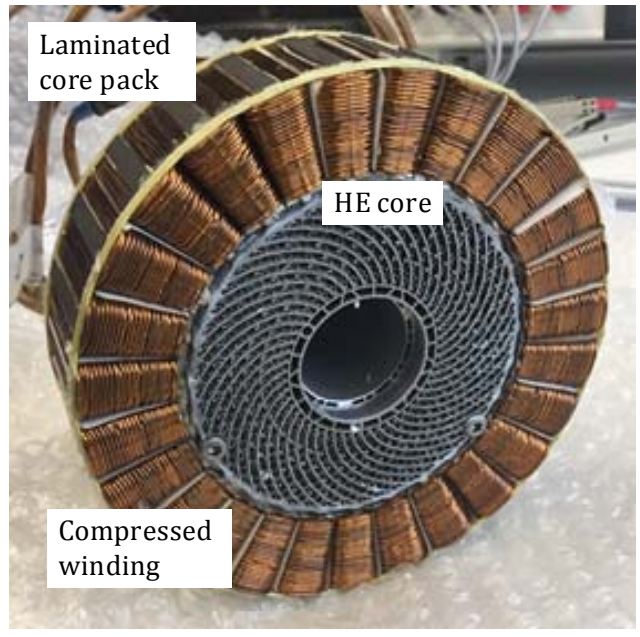

Fig. 5. Complete stator-winding assembly with integrated HE

using both hot-wire and Pitot tubes to cross check the measurements. To measure the pressure-drop a combination of static pressure probe, Pitot tube and micro-manometer was used. The Pitot tube was used on the $\mathrm{HE}$ inlet to simultaneously monitor the airflow speed, and the static pressure probe was place at the HE outlet. Due to the specific 'donut' shape of the HE body a guide to the airflow was introduced. The 'cigar' shaped assembly covering the shaft mounting of the HE assembly is shown in Fig. 2a). The heating element was built using an array of surface mounted power resistors and an interfacing ring, Fig. 2b). The heating element is supplied from a dc power supply, allowing for precise control of the power (heat) dissipated by the integrated HE. The outer periphery of the heating element is thermally insulated to assure one-dimensional heat transfer from the heat source to the heat sink. Such an experimental setup allows for HE characterisation, which is decoupled from other hardware development activities, e.g. fabrication of the motor active parts.

\section{B. Testing Procedure}

The testing procedure includes initial setting of the input control quantities, which are the airflow velocity and input power for the heating element. All the quantities, including data from thermal sensors, are logged using a data acquisition system allowing for thermal steady state or transient performance of the $\mathrm{HE}$ to be analysed. The thermal sensors (type-K thermocouples) are placed in several places in the test rig, including the HE, heating element, input and output air. It is important to note that multiple thermal sensors for selected measuring points are used to provide more reliable, averaged thermal readings. For the purpose of mapping HE performance, thermal steady state testing was used. Here, the thermal equilibrium was defined as the temperature change of heating element lower than $1^{\circ} \mathrm{C}$ over 10 minutes. A complete $\mathrm{HE}$ performance map includes several inlet airflow velocities and input powers. The HE inlet temperature was pre-set to approximately $+20^{\circ} \mathrm{C}$ for all tests.

At a later stage of the research, when all active parts of the motor were fabricated, thermal tests on the complete stator-winding with integrated $\mathrm{HE}$ assembly were performed to emulate the take-off operating condition. The complete assembly is shown in Fig. 5. For this high-torque, 
low-speed operation majority of power losses are generated in the winding, $250 \mathrm{~W}$. It was assumed here that the HE is the only heat path for removing the generated heat. This represents the worst case scenario, where other subassemblies of the motor do not contribute to the overall heat removal from the motor body.

\section{RESULTS AND OBSERVATIONS}

\section{A. HE Performance Mapping}

Performance mapping of the alternative HE designs was performed using the analytical and experimental approaches described earlier. Fig. 6 presents calculated results, assuming an inlet air temperature of $+30^{\circ} \mathrm{C}$ and the temperature of the $\mathrm{HE}$ outer diameter surface/wall to be $+90^{\circ} \mathrm{C}\left(+60^{\circ} \mathrm{C}\right.$ temperature difference). Both heat transfer rate and pressure drop across HE body are shown. The initial HE exchanger design was focused predominantly on the thermal performance ( $1^{\text {st }}$ iteration of the exchanger with 51 fins). Consequently, the HE design was conservative with active surface area to volume ratio equal to $2696 \mathrm{~m}^{2} / \mathrm{m}^{3}$. Later, after a more detailed analysis of the thermal system, the pressure drop requirement was defined. It was found that the pressure drop is too high for the $1^{\text {st }}$ iteration of HE to encourage sufficient airflow through the HE core. The data gathered from the analyses and tests on the $1^{\text {st }}$ iteration of $\mathrm{HE}$ was used to inform design of the $2^{\text {nd }}$ iteration of HE.

a)

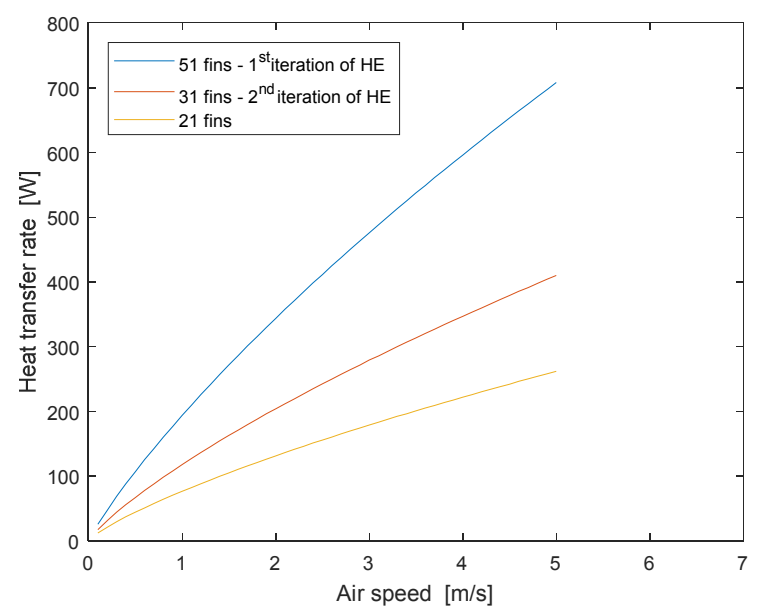

b)

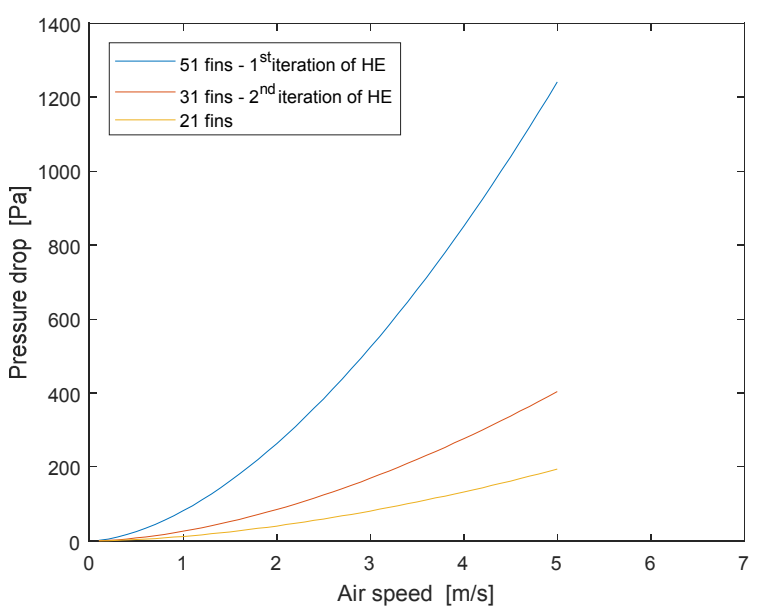

Fig. 6. Calculated performance measures for alternative HE designs, a) heat transfer rate, b) pressure drop a)

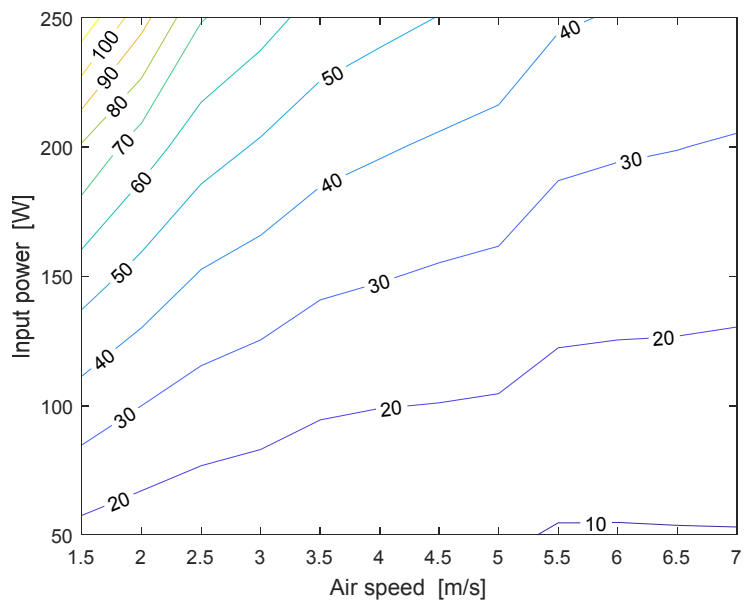

b)

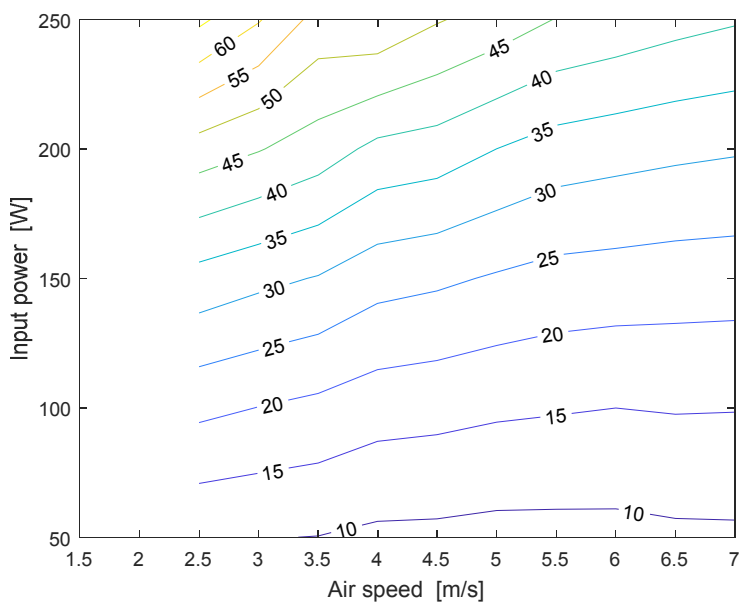

Fig. 7. Input power versus airspeed, a) $1^{\text {st }}$ iteration of $\mathrm{HE}$, b) $2^{\text {nd }}$ iteration of $\mathrm{HE}$ at normal temperature and atmospheric pressure; isotherms temperature in ${ }^{\circ} \mathrm{C}$

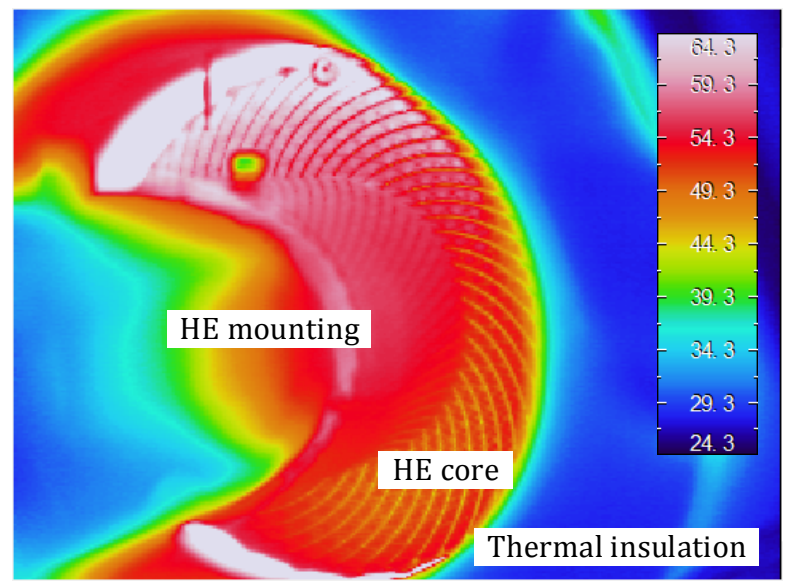

Fig. 8. Infrared image illustrating temperature distribution at the HE outlet, $\left(1^{\text {st }}\right.$ iteration of $\left.\mathrm{HE}\right)$; temperature in ${ }^{\circ} \mathrm{C}$

To reduce the pressure drop the number of HE fins was reduced, see Fig.6. Clearly, reducing the number of fins has a significant impact on both the heat transfer rate and pressure drop as shown in Fig. 6. After an iterative design process, a HE design which provides a 'good' compromise between both performance measures was selected. Here, $70 \%$ pressure drop and $40 \%$ heat transfer rate reduction were achieved. The 
$2^{\text {nd }}$ iteration of HE exchanger has an active surface area to volume ratio equal to $961 \mathrm{~m}^{2} / \mathrm{m}^{3}$ and overall assembly weight reduced by $20 \%$ when compared with the $1^{\text {st }}$ iteration of $\mathrm{HE}$.

It is important to note that applicability of the 1D analytical approach used in this work is limited to compact HEs like the $1^{\text {st }}$ iteration of HE ('high' surface area to volume ratio). Thus, it was expected that performance predictions for the heat transfer rate might be less accurate for the $2^{\text {nd }}$ interaction of HE. Fig. 7 presents performance maps derived from tests on the HEs. Here, the input power is representative of HE heat transfer rate and airspeed refers to HE inlet air velocity at normal temperature and atmospheric pressure. The characteristic isolines on the contour plots shown in Fig. 7 represent temperature difference between the inlet air and HE heating element. Such data accounts for contact thermal resistance between the $\mathrm{HE}$ and heating element or statorwinding assembly, where appropriate. It is worth mentioning that a tight sliding fit with accompaniment of thermal paste was used here to provide a 'good' thermal contact between the interfacing parts.

When comparing the isotherms for both HE designs, it is evident that the prototypes are capable of removing the power loss of $250 \mathrm{~W}$ required for the take off. Closer analysis suggest that the HEs' performance is comparable at low air velocity, but at high airspeed the $1^{\text {st }}$ iteration of $\mathrm{HE}$ is $12 \%$ more effective in removing heat than the $2^{\text {nd }}$ iteration of $\mathrm{HE}$. As the lower end of the inlet airspeed is of particular interest here, the $2^{\text {nd }}$ iteration of $\mathrm{HE}$ provides an all around solution for the aircraft application. Interestingly, the measured heat removal rate for the $2^{\text {nd }} \mathrm{HE}$ is better than suggested by the analytical predictions. This was attributed to the limitations of the 1D analytical approach employed here. The heat transfer and pressure drop measurements were supplemented with thermal measurements (thermal imaging) to assess the HE behaviour in terms of heat distribution across the HE's core. Fig. 8 shows an example of measured temperature distribution at the HE outlet ( $1^{\text {st }}$ iteration of HE). The uniform temperature distribution confirms superior thermal path (thermal conductivity) of the HE body. This enables very effective heat removal from the stator-winding.

Fig. 9 presents the measured and calculated data from pressure drop tests on the HE prototypes. The results show similar trends, with relatively good correlation at the lower end of the airspeeds considered here. The measured data from tests

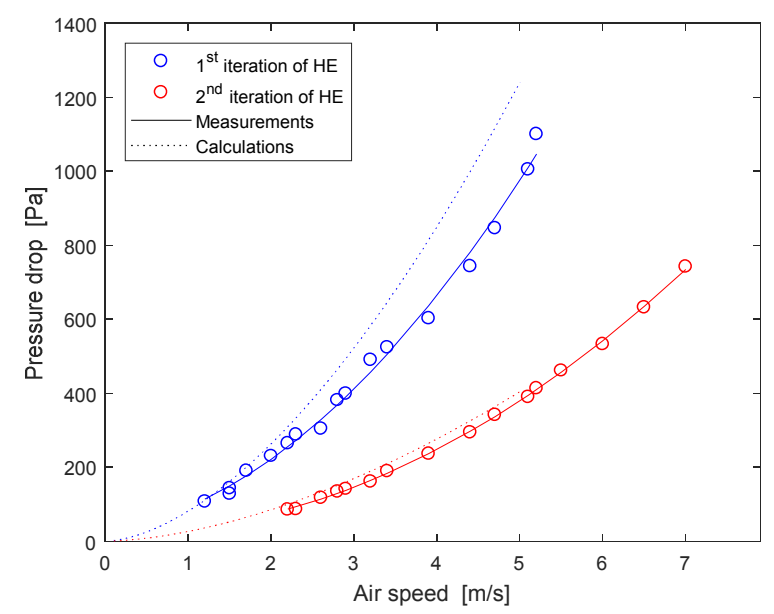

Fig. 9. Measured and calculated pressure drop across HE body

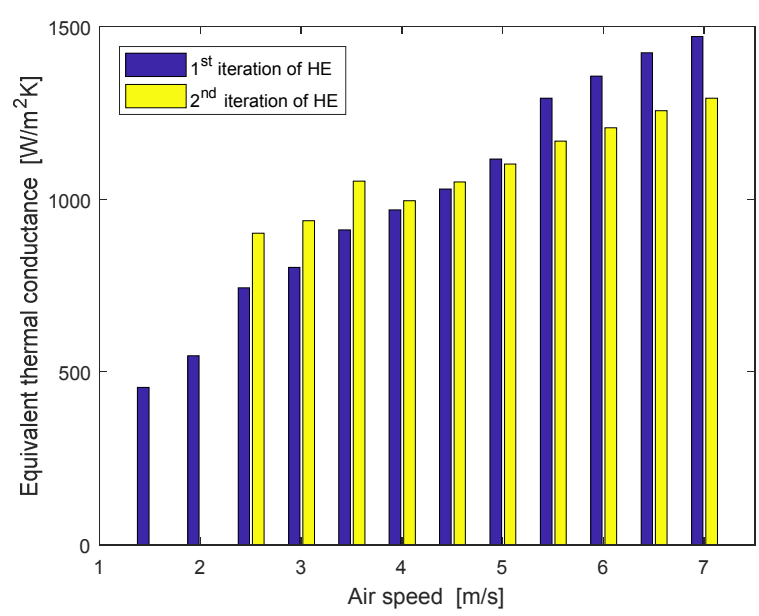

Fig. 10. Equivalent thermal conductance across from the heat source (heating element ) to the heat sink (HE)

on HE can also be used to derive an equivalent thermal conductance for the stator inner bore. This is particularly useful when analysing the thermal performance of the statorwinding assembly or complete motor. Fig. 10 shows the variation of the equivalent thermal conductance versus the inlet airspeed derived for $250 \mathrm{~W}$ power loss generated in the heating element. The results provide a clear insight into the HEs' performance across the air velocity range. It is interesting to note that both HEs proved similar heat removal capabilities for an inlet airflow from $4 \mathrm{~m} / \mathrm{s}$ to $5 \mathrm{~m} / \mathrm{s}$.

Another important factor when considering the active fluid cooling is the hydraulic power loss or pumping power [9] required to sustain required volumetric mass flow. Following Poiseuillie's law, the hydraulic power loss can be expressed as follows,

$$
W_{p}=\dot{v} \Delta P_{\text {total }}=\frac{\dot{m} \Delta P_{\text {total }}}{\rho}
$$

where: $\dot{v}$ is the volumetric flow rate.

Here, for the lower end of the inlet air velocity expected at the take off operation, e.g. $2 \mathrm{~m} / \mathrm{s}$, the hydraulic power loss is equal to $2.5 \mathrm{~W}$ and $0.8 \mathrm{~W}$ for the $1^{\text {st }}$ and $2^{\text {nd }}$ iteration of the HEs respectively. For the high altitude cruise operation the pressure drop across the HE core is expected to be significantly lower due to the reduced density of the air (air density is approximately 14 times lower at $20 \mathrm{~km}$ cruise than at sea level). Consequently, the hydraulic power loss should not be an issue at the high altitude, high efficiency operation. The hydraulic power loss figures provided here have an indicative character only as they do not account for the motor aerodynamic ducting/enclosure, which is a part of the complete motor assembly with integrated HE.

\section{B. Integrated HE Stator-Winding Thermal Testing}

Although the performance mapping exercise showed that the HE meets all design targets set out for the thermal management system, it does not provide any information regarding thermal behaviour of the complete motor. As outlined earlier, it is possible to use the data from tests on HEs to perform supplementary thermal analyses and gain more understanding on how both the $\mathrm{HE}$ and stator-winding assemblies interact together as a complete unit. However, as the machine design considered here is rather unusual in terms 
a)

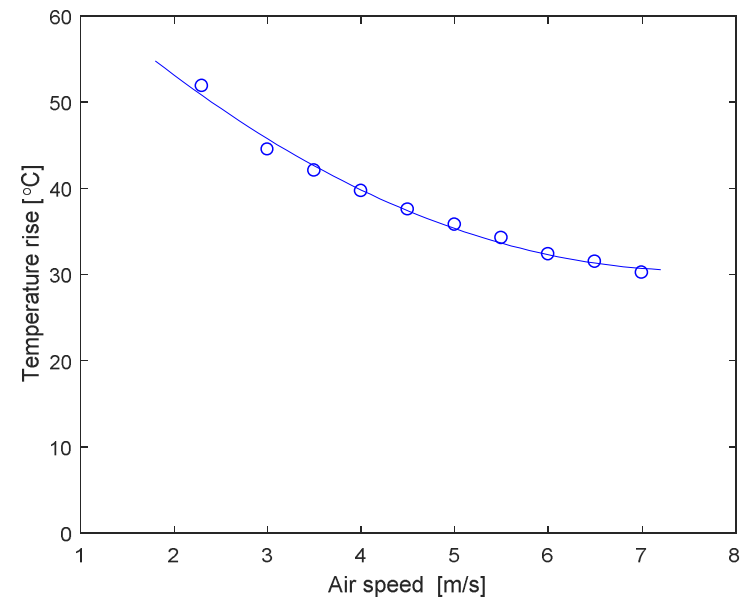

b)

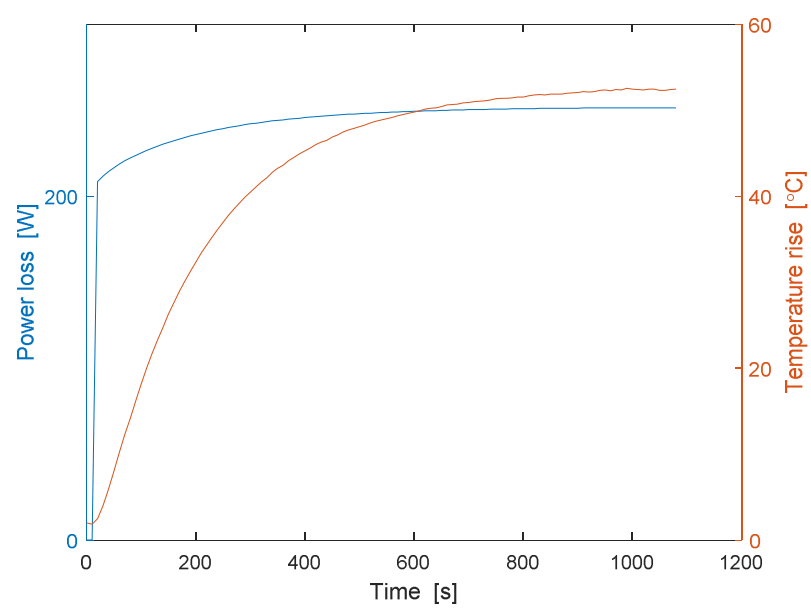

Fig. 11. Measured thermal data from tests on the stator-winding with integrated $\mathrm{HE}$, a) winding hot-spot temperature above $\mathrm{HE}$ inlet air temperature versus HE inlet air velocity, b) winding hot spot thermal transient for $250 \mathrm{~W}$ input power loss, $\left(2^{\text {nd }}\right.$ iteration of $\left.\mathrm{HE}\right)$

of manufacturing and assembly processes used, it would be challenging to theoretically derive or estimate all build factors, which are necessary for reliable temperature predictions. It was decided that hardware tests on the statorwinding assembly with the $\mathrm{HE}$ in place provide a better alternative. To emulate the take off operating condition, the complete stator-winding assembly with integrated $\mathrm{HE}$ was instrumented and mounted on the test rig, as described in the earlier section of the paper. The experiment was set up such that the winding generated heat is removed by the HE only This represent the worst case scenario, were the motor outer surfaces do not take active part in dissipating the heat, i.e. the stator-winding body is thermally insulated.

Fig. 11a) presents measured variation of the winding hot spot temperature rise above HE inlet air temperature versus HE inlet air velocity. It is evident that the complete statorwinding with $\mathrm{HE}$ in place performs very well, even at the lower end of the operating air speed range. e.g., assuming $2 \mathrm{~m} / \mathrm{s}$ airflow speed into the $\mathrm{HE}$ core results in $+55^{\circ} \mathrm{C}$ winding hot spot temperature rise. This provides a sufficient margin for the aircraft launch in a hot environment $\left(+45^{\circ} \mathrm{C}\right)$ or any issues associated with a less regular inlet airflow, e.g. swirl effect introduced by the aircraft propeller.
Fig. 11b) shows an example of measured thermal transient for the stator-winding with integrated $\mathrm{HE}$, for $250 \mathrm{~W}$ input power loss. Both the input power loss and winding hot spot temperature rise are shown in Fig. 10b). It is important to note that the input power loss was selected here to account for the winding operating at elevated temperature, i.e. characteristic increase of the input power loss to $250 \mathrm{~W}$ at thermal equilibrium as the winding heats up is presented. Here, the thermal transient is relatively short, less than $20 \mathrm{mins}$, due to the low mass of the motor (complete motor weight is less than $1.5 \mathrm{~kg}$ ). Considering that it takes several hours for the aircraft to reach the high altitude operating conditions, the propulsion motors need to sustain steady state operation at thermal equilibrium.

\section{CONCLUSIONS}

This paper highlights selected design challenges and design processes associated with development of a thermal management system for an electric propulsion system of a high altitude solar air craft. The research focus was placed on an integrated, air cooled HE concept for the electric motors, which are an integral part of the electric drive train. To accommodate for all design requirements associated with reliable and efficient operation of the motors, a number of HE concepts were considered. An additive manufacturing process with powder bed and selective laser melting was employed here to achieve ultra-lightweight HE design, which provides both the effective heat extraction from the motor body and mechanical support for motor subassemblies, e.g. stator, rotor, resolver and motor mounting.

Two HEs were designed, fabricated and tested as a part of the development process. The experimentally informed, iterative process adopted in this research allowed for a more dependable design approach. This is evidenced by the early computational design studies, where some of the HE's predicted performance measurements deviated considerably from the experimental data. e.g. it was shown that the use of a 1D design approach is limited to HEs with a high ratio of the core surface area to volume. The design process was then finely tuned by the use of measured data from previous developments of HEs and high fidelity CFD analyses. The experimental setup developed to characterise HE concepts was a key element of the design process as it allowed for a repeatable and relatively quick assessment of all $\mathrm{HE}$ performance measurements in a controlled environment.

It has been shown that the developed thermal management system assures healthy operation of the motors for both take off and cruise working duties. The measured results show that the more challenging take off operation is guaranteed by the sufficient temperature margin for the winding assembly ( $2^{\text {nd }}$ iteration of HE). The temperature margin accommodates the elevated ambient temperature and 'chaotic' inlet airflow as a combined effect from the aircraft propellers and motor aerodynamic enclosure. Both the fluid mechanic effects are difficult to replicate in a low-scale wind tunnel experiment or CFD. It is believed that the HE upstream surfaces should ideally be designed to accommodate the nonaxial velocity profile created by the swirl, i.e. the propeller action (suggesting that a flow passage normal to the undisturbed flow path may not be ideal). This phenomenon will be examined in the future experimental characterisation of the HE. 


\section{APPENDIX}

The experimental friction factor can be extracted from measured pressure drop data to inform the pressure drop modelling,

$$
f_{\text {exp }}=\frac{\rho_{m} D_{h}\left(\Delta P_{\text {exp }}-\Delta P_{\text {minor losses }}\right)}{2 G^{2} L}
$$

where:

$$
\begin{aligned}
\Delta P_{\text {minor losses }}= & \frac{G^{2}}{2 g \rho_{i}}\left[\left(1-\sigma^{2}+K_{c}\right)\right. \\
& +2\left(\frac{\rho_{i}}{\rho_{o}}-1\right) \\
& \left.-\left(1-\sigma^{2}-K_{e}\right)\left(\frac{\rho_{i}}{\rho_{o}}\right)\right]
\end{aligned}
$$

and $\Delta P_{\text {exp }}$ is the experimentally derived pressure drop across the HE body.

The inlet and outlet fluid (air) densities, mass flux and $R e$ can be calculated as follow,

$$
\rho=\frac{P}{R T}, G=\frac{\dot{m}}{A_{f}}, R e_{D_{h}}=\frac{G D_{h}}{\mu}
$$

where: $P$ is the air pressure, $R$ is the universal gas constant, $R=287.04 \mathrm{~J} / \mathrm{kg} \cdot \mathrm{K}$ and $T$ is the air temperature, $A_{f}$ is the free flow area and $\mu$ is the fluid (air) viscosity.

To inform the heat transfer modelling, the $\eta_{o}, R_{w}$ and $h$ can be derived as follows,

$$
\begin{aligned}
& R_{w}=\frac{\delta_{w}}{A_{w} k_{w}}, h=\frac{J G c_{p}}{\operatorname{Pr}^{\frac{2}{3}}} \\
& \eta_{\text {fin }}=\frac{\tanh \left(m l_{\text {fin }}\right)}{m l_{\text {fin }}}, m=\sqrt{\frac{2 h}{k_{\text {fin }} \delta_{\text {fin }}}}
\end{aligned}
$$

where: $\delta_{w}$ is the plate wall thickness, $A_{w}$ is the wall surface area, $k_{w}$ is the thermal conductivity of the wall material, $J$ is the Colburn factor, $P r$ is the Prandtl number, $\eta_{f i n}$ is the fin efficiency, $l_{\text {fin }}$ is the fin length, $m$ is the standard extended surface parameter, $\delta_{f i n}$ is the fin thickness and $k_{f i n}$ is the thermal conductivity of the fin material.
The overall fin efficiency for the HE with surface area of fins, $A_{\text {fin }}$, is therefore,

$$
\eta_{o}=\left[1-\left(1-\eta_{\text {fin }}\right) \frac{A_{\text {fin }}}{A}\right]
$$

\section{REFERENCES}

[1] S. Ullah, M. Kimiabeigi, B. Scholes, A. Steven, R. Wrobel, W. Davis, J. Widmer, "Optimisation of Permanent Magnet Machine Topologies Suitable for Solar Powered Aircraft," XXIII International Conference on Electrical Machines, ICEM'2018, Alexandroupoli, Greece, September 2018, pp. $332-338$.

[2] J. D. Widmer, C. M. Spargo, G. J. Atkinson, B. C. Mecrow, "Solar Plane Propulsion Motors with Precompressed Aluminium Stator Windings," IEEE Transactions on Energy Conversion, vol. 29, no. 3, September 2014, pp. $681-688$.

[3] B. C. Mecrow, J. W. Bennett, A. G. Jack, D. J. Atkinson, A. J. Freeman, "Drive Topologies for Solar-Powered Aircraft," IEEE Transactions on Industrial Electronics, vol. 57, no. 1, January 2010, pp. 457 - 464.

[4] P. A. Hargreaves, B. C. Mecrow and R. Hall, "Calculation of Iron Loss in Electrical Generators Using Finite-Element Analysis," IEEE Transactions on Industry Applications, vol. 48, no. 5, SeptemberOctober 2012, pp. $1460-1466$.

[5] C. R. Sullivan, "Computationally Efficient Winding Loss Calculation with Multiple Windings, arbitrary waveforms, and two-dimensional or three-dimensional field geometry," IEEE Transactions on Power Electronics, vol. 16, no. 1, January 2001, pp. $142-150$.

[6] A. Hussein, "Additive Manufacturing of Compact Heat Exchangers," 34th Heat Exchanger Action Group Meeting, HEXAG'2017, Newcastle upon Tyne, Newcastle University, June 2017 (www.hexag.org).

[7] S. Wang, Y. Li, Y-Z. Li, J. Wang, X. Xiao, W. Guo, "Conception and Experimental Investigation of a Hybrid Temperature Control Method using Phase Change Material for Permanent Magnet Synchronous Motors," Experimental Thermal and Fluid Science, Elsevier, vol. 81, October 2017, pp. $9-20$.

[8] W. M. Kays and A. L. London, Compact Heat Exchangers, Third Edition, Krieger Publishing Company, London, 1998.

[9] J. E. Hesselgreaves, R. Law, D. A. Reay, Compact Heat Exchangers Selection, Design and Operation, Second Edition, Elsevier, 2016.

[10] B. Sunden, J. Fu, Hear Transfer in Aerospace Applications, Elsevier Ltd., London, 2017.

[11] B. Massey, A. Ward-Smith, Mechanics of Fluids, Spon/Taylor \& Francis, London, 2012.

[12] R. C. Pankhurst, D. W. Holder, Wind-Tunnel Technique, Sir Isaac Pitman \& Sons, Ltd., London, 1968.

[13] R. Wrobel, B. Scholes, A. Hussein, R. Law, A. Mustaffar, D. Reay, "A Metal Additively Manufactured (MAM) Heat Exchanger for Electric Motor Thermal Control on a High-Altitude Solar Aircraft Experimental Characterisation," Proceedings of the $16^{\text {th }}$ UK Heat Transfer Conference, (UKHTC'2019), Nottingham, UK, September 2019 , pp. $1-5$. 